\title{
Two polymorphs of 4-(4-hexyloxyphenyl)-2,6-di(pyrazin-2- yl)pyridine and the crystal structure of its copper(II) complex
}

\author{
Li Li, ${ }^{a}$ Yuan Zhuo Zhang, ${ }^{\mathrm{b}}$ Chengxiong Yang, ${ }^{\mathrm{a}}$ E Liu, ${ }^{\mathrm{a}}$ James C. Fettinger ${ }^{\mathrm{c}}$ and Guoqi Zhang ${ }^{\mathrm{b}}$ \\ ${ }^{a}$ College of Chemical Engineering and Pharmacy, Jingchu University of Technology, Jingmen 448000, China \\ ${ }^{b}$ Department of Sciences, John Jay College and The Graduate Center, The City University of New York, \\ New York, NY 10019, USA \\ ${ }^{c}$ Department of Chemistry, University of California Davis, Davis, CA 95616, USA \\ *Corresponding author. Email address: guzhang@jjay.cuny.edu
}

Keywords: Polymorphism; Polydentate ligand; Crystal structure; Copper(II); Coordination complex

\begin{abstract}
4-(4-Hexyloxyphenyl)-2,6-di(pyrazin-2-yl)pyridine (1), an analogue of the archetypal ligand, 2,2':6', 2"-terpyridine containing additional outer N-donating sets is synthesized through the facile one-step Kröhnke condensation reaction. It is observed that different crystallization conditions affect the molecular packing in $\mathbf{1}$ and as a result two crystal polymorphs are resolved via single-crystal X-ray diffraction analysis. Distinct intermolecular $\pi \ldots \pi$ interactions were found to play a crucial role in driving the formation of polymorphism. The complexation of this ligand with copper(II) dichloride resulted in the formation of a mononuclear complex with $\mathrm{Cu}^{\mathrm{II}}$ being in the chelating cavity of $\mathbf{1}$. X-ray structural analysis confirms that this is the only product even though the synthesis was conducted under various conditions, remarkably different from the known structure with three $\mathrm{Cu}^{\mathrm{II}}$ cores.
\end{abstract}

\section{Introduction}

2,2':6',2"-Terpyridine (2,2':6',2"-tpy) is a convergent tridentate ligand that contains an ideal $\mathrm{N}_{3}$ binding cavity for metal ions [1]. Therefore, since its observation it and its 4'-substituted derivatives have been extensively explored for the construction of both small molecular coordination complexes and extended metallosupramolecules, which have found tremendous applications in host-guest chemistry, molecular recognition and sensing, luminescent and magnetic materials, and catalysis [2-9]. 2,6-di(pyrazin-2-yl)pyridine (L) containing a similar heterotricyclic moiety is structurally analogous to $2,2^{\prime}: 6^{\prime}, 2^{\prime \prime}-$ tpy, yet it bears two additional $\mathrm{N}$ 
coordination sites for metal ions except for the $\mathrm{N}_{3}$ chelating cavity. Versatile coordination chemistry for this type of ligands is therefore much anticipated [10]. However, compared to 2, 2':6',2"-tpy, $\mathbf{L}$ and its derivatives were relatively less explored for transition metal coordination chemistry [11-14]. Although examples including $\mathrm{Cd}^{\mathrm{II}}, \mathrm{Ni}^{\mathrm{II}}, \mathrm{Fe}^{\mathrm{II}}$ and $\mathrm{Ru}^{\mathrm{II}}$ complexes based on 4-substituted derivatives of $\mathbf{L}$ were known several year ago, mononuclear complexes employing only the chelating $\mathrm{N}_{3}$ site of ligands were formed in almost all cases and the outer $\mathrm{N}$-donors remain uncoordinated [11-14]. To further understand the coordination chemistry of this type of ligand and explore the coordination ability of the additional outer $\mathrm{N}$-donors, we have recently prepared a simple derivative, 4-phenyl-2,6-di(pyrazin-2-yl)pyridine through the classic Kröhnke condensation reaction similar to that for 2,2':6',2"-tpy ligands, and studied its reactions towards copper(II), zinc(II), Co(II) and Fe(II) salts [10]. Although in most of the complexes isolated from these reactions the ligands adopt traditional tridentate binding for metals within the inner $\mathrm{N}_{3}$ cavity, an unprecedented trinuclear bis-ligand copper(II) complexes was characterized, in which the outer- $\mathrm{N}$ coordination was for the first time disclosed. We are, therefore, interested to expand the studies by introducing other substituents in the 4-position of $\mathbf{L}$, and to prepare novel metal complexes with the new ligands.

Polymorphism, a terminology that depicts the occurrence of a compound in more than one crystalline form is an important phenomenon in chemistry, pharmacology and materials science [15]. The study of polymorphism in organic compounds or metal-organic complexes/networks has received increasing attention over the past decades [16]. In particular, in pharmaceutical industry to control the formation of a particular polymorph of molecular crystals with desired properties is of special interest. However, it is a very challenging task for scientists to predict and/or control new polymorphic forms for certain molecules, because weak and non-directional intermolecular interactions are often the governing forces for the generation of polymorphism.

To continue our recent efforts on the coordination chemistry of 2,2':6',2"-tpy derived nitrogen ligands $[17,18]$, herein we present the facile one-step synthesis of a new derivative of L, 4-(4-hexyloxyphenyl)-2,6-di(pyrazin-2-yl)pyridine (1, Scheme 1) and its structural characterization. Interestingly, we serendipitously observe two crystalline polymorphs for this compound while we are exploring the coordination chemistry with transition metals. The solid-state structures of both polymorphs are described and compared with each other. In addition, we utilize the ligand to prepare a new copper(II) complex which features a mononuclear structure, in contrast to the previously reported trinuclear complex of $\mathbf{L}$ having a different 4-substituent [10]. 


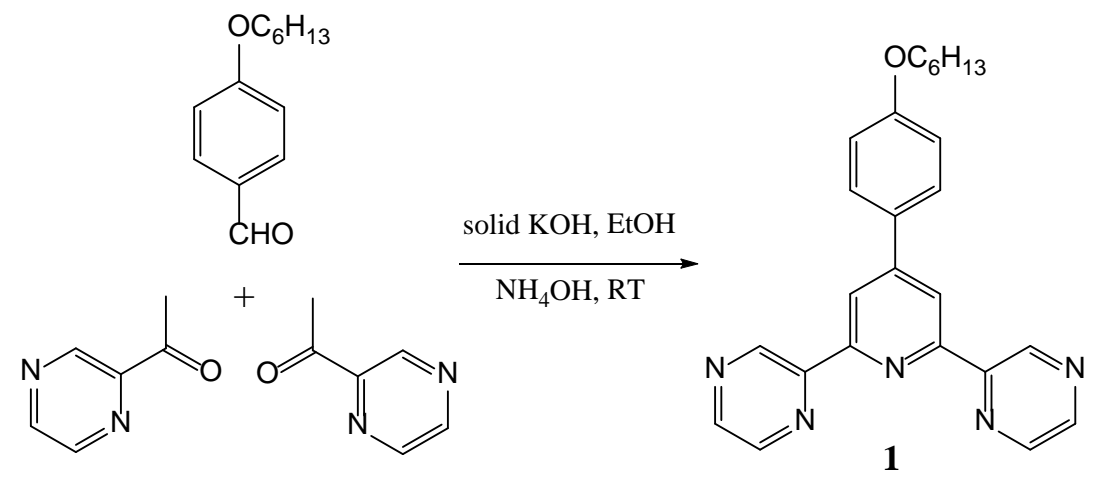

Scheme 1. The one-step synthesis of ligand 1.

\section{Experimental}

\subsection{General}

Solvents and reagents were purchased from Fisher Scientific or Sigma-Aldrich in the US. All reactions were performed under ambient conditions (no inert atmosphere). FT-IR spectra were measured on a Shimadzu 8400S instrument with solid samples using a Golden Gate ATR accessory. ${ }^{1} \mathrm{H}$ and ${ }^{13} \mathrm{C}$ NMR spectra were obtained at room temperature on a Bruker III $500 \mathrm{MHz}$ spectrometer with TMS as an internal standard. High resolution mass spectra were recorded on an Agilent 6550 iFunnel ESI-QTOF-LC/MS instrument. Elemental Analyses were performed by Midwest Microlab LLC in Indianapolis.

\subsection{Synthesis of 1}

In a $250 \mathrm{~cm}^{3}$ round-bottom flask equipped with a magnetic stirrer, 2-acetylpyrazine (2.44 g, 20.0 mmol) was added to a solution of 4 -hexyloxybenzaldehyde (2.06 g, $10.0 \mathrm{mmol})$ in EtOH $\left(50 \mathrm{~cm}^{3}\right)$. $\mathrm{KOH}$ pellets $(0.56 \mathrm{~g}, 10 \mathrm{mmol})$ were then added, followed by aqueous $\mathrm{NH}_{3}\left(28 \%, 40 \mathrm{~cm}^{3}\right)$. The resulting orange solution was stirred at room temperature overnight, during which time a suspension had formed. White solid was collected by filtration, washed with $\mathrm{H}_{2} \mathrm{O}$ and $\mathrm{EtOH}$, and dried in vacuo over $\mathrm{P}_{2} \mathrm{O}_{5}$. Yield: $2.28 \mathrm{~g}$ (55\%). Crystals of polymorph 1a was grown by slow evaporation of a solution of $\mathbf{1}$ in DCM-MeOH over one week. Crystals of polymorph $\mathbf{1 b}$ was obtained by slow evaporation of a DCM-MeCN solution containing 1 and $\operatorname{AgPF}_{6}$ (2.0 equiv.). ${ }^{1} \mathrm{H}$ NMR (500 MHz, $\left.\mathrm{CDCl}_{3}\right) \delta 9.39(\mathrm{~d}, J=2.0 \mathrm{~Hz}, 2 \mathrm{H}$ ), 8.72 (dd, $J=4.5,1.5 \mathrm{~Hz}, 2 \mathrm{H}), 8.54$ (dt, $\left.J=8.0,2.0 \mathrm{~Hz}, 2 \mathrm{H}\right), 7.95$ (s, 2 H), 7.73 (dd, $J=7.0,2.0 \mathrm{~Hz}, 2 \mathrm{H}), 7.49$ (dd, $J=13.0,5.0 \mathrm{~Hz}, 2 \mathrm{H}$ ), 7.08 (d, $J=8.5 \mathrm{~Hz}, 2 \mathrm{H}$ ), 4.07 (t, $J=6.5 \mathrm{~Hz}, 2 \mathrm{H}), 1.86$ (m, $2 \mathrm{H}), 1.52$ (m, $2 \mathrm{H}), 1.39$ (m, $4 \mathrm{H}), 0.95$ (t, $J=7.0 \mathrm{~Hz}, 3 \mathrm{H}) \mathrm{ppm}$. ${ }^{13} \mathrm{C}$ NMR $\left(125 \mathrm{MHz}, \mathrm{CDCl}_{3}\right) \delta 160.48,155.21,150.45,149.97,148.25,134.89,134.73,130.04$, 
128.33, 123.71, 117.23, 115.26, 68.26, 31.60, 29.19, 25.74, 22.64, 14.09 ppm. FT-IR (solid, $\mathrm{cm}^{-1}$ ): 1600m, 1515s, 1376m, 1260s, 1182s, 1110m, 1033s, 1016s, 850w, 826s, 607m. HR-MS: m/z $434.1943[\mathrm{M}+\mathrm{Na}]^{+}$(calc. 434.1957), 412.2132 [M + H] ${ }^{+}$(base peak, calc. 412.2137).

\subsection{Synthesis of $\mathrm{Cu}(\mathbf{1}) \mathrm{Cl}_{2} \cdot \mathrm{CH}_{3} \mathrm{CN}$ (2)}

A solution of 1 (41.1 mg, $0.100 \mathrm{mmol})$ in $\mathrm{MeOH} / \mathrm{CH}_{2} \mathrm{Cl}_{2}\left(10 \mathrm{~cm}^{3}, 1: 4, \mathrm{v} / \mathrm{v}\right)$ was placed in a test tube. A mixture of $\mathrm{MeCN}$ and $\mathrm{CH}_{2} \mathrm{Cl}_{2}\left(5 \mathrm{~cm}^{3}, 4: 1, \mathrm{v} / \mathrm{v}\right)$ was layered on the top of this solution, followed by a solution of $\mathrm{CuCl}_{2} \cdot 2 \mathrm{H}_{2} \mathrm{O}(34.0 \mathrm{mg}, 0.200 \mathrm{mmol})$ in $\mathrm{MeOH}\left(10 \mathrm{~cm}^{3}\right)$. The tube was sealed and allowed to stand at room temperature for two weeks. X-ray quality green crystals of 2 were isolated by decanting the solvent and washed with $\mathrm{MeOH}$, and dried in air. Yield: $46.0 \mathrm{mg}$ (85\% based on 1). FT-IR (solid, $\mathrm{cm}^{-1}$ ) 2929w, 1594s, 1523m, 1469s, 1397s, 1310m, 1288w, 1246s, 1196s, 1153m, 1077s, 1038s, 1014m, 849s, 612m. Anal. Calcd. for $\mathrm{C}_{25} \mathrm{H}_{25} \mathrm{Cl}_{2} \mathrm{CuN}_{5} \mathrm{O} \cdot \mathrm{CH}_{3} \mathrm{CN}$ : C 55.25, H 4.81, N 14.32\%. Found C 55.01, H 4.85, N 13.98.

\subsection{X-ray Structural Determinations}

Suitable crystals of 1a, $\mathbf{1 b}$ and $\mathbf{2}$ were mounted on Cryoloops with Paratone-N oil. Data were collected with a Bruker APEX II CCD using Mo-K $\alpha$ radiation and corrected for absorption with SADABS and structures solved by direct methods. All non-hydrogen atoms were refined anisotropically by full-matrix least squares on $\mathrm{F}^{2}$. Hydrogen atoms were found from Fourier difference maps and refined isotropically, otherwise they were placed in calculated positions with appropriate riding parameters. Crystal structures and packing figures were drawn with the program Mercury v. 2.4. The crystallographic refinement data are listed below.

1a: $\mathrm{C}_{25} \mathrm{H}_{25} \mathrm{~N}_{5} \mathrm{O}, M=411.50$, colorless parallelepiped, triclinic, space group $P-1, a=8.5808$ (2), $b=$ 8.8979(2), $c=14.4976(4) \AA, \alpha=72.3759(9), \beta=89.3456(10), \gamma=78.9756(10), U=1034.21(4) \AA^{3}, Z$ $=2, D_{c}=1.321 \mathrm{Mg} \mathrm{m}^{-3}, \mu(\mathrm{Mo}-\mathrm{K} \alpha)=0.084 \mathrm{~mm}^{-1}, T=90(2) \mathrm{K}$. Total 9253 reflections, 4739 unique. Refinement of 4739 reflections (380 parameters) with $I>2 \sigma(I)$ converged at final $R_{1}=0.0359\left(R_{1}\right.$ all data $=0.0401), w R_{2}=0.1028\left(w R_{2}\right.$ all data $\left.=0.1073\right), \mathrm{GOF}=1.037$.

1b: $\mathrm{C}_{25} \mathrm{H}_{25} \mathrm{~N}_{5} \mathrm{O}, M=411.50$, colorless arrowhead plate, triclinic, space group $P-1, a=5.2210(7), b=$ 12.1281(17), $c=18.331(2) \AA, \alpha=101.851(3), \beta=90.4776(18), \gamma=93.3741(16), U=1040.3(2) \AA^{3}, Z$ $=2, D_{c}=1.314 \mathrm{Mg} \mathrm{m}^{-3}, \mu(\mathrm{Mo}-\mathrm{K} \alpha)=0.083 \mathrm{~mm}^{-1}, T=90(2) \mathrm{K}$. Total 9442 reflections, 4787 unique. Refinement of 4787 reflections (381 parameters) with $I>2 \sigma(I)$ converged at final $R_{1}=0.0397\left(R_{1}\right.$ all data $=0.0439), w R_{2}=0.1126\left(w R_{2}\right.$ all data $\left.=0.1178\right), \mathrm{GOF}=1.045$. 
2: $\mathrm{C}_{27} \mathrm{H}_{28} \mathrm{Cl}_{2} \mathrm{CuN}_{6} \mathrm{O}, M=586.99$, green block, monoclinic, space group $P 2(1) / c, a=21.7193(6), b=$ 17.9642(5), $c=13.7929(4) \AA, \beta=99.6350(10), U=5176.1(3) \AA^{3}, Z=8, D_{c}=1.478 \mathrm{Mg} \mathrm{m}^{-3}, \mu$ (Mo$\mathrm{K} \alpha)=3.296 \mathrm{~mm}^{-1}, T=120(2) \mathrm{K}$. Total 36455 reflections, 7265 unique. Refinement of 10010 reflections (689 parameters) with $I>2 \sigma(I)$ converged at final $R_{1}=0.0538\left(R_{1}\right.$ all data $\left.=0.0783\right), w R_{2}$ $=0.1342\left(w R_{2}\right.$ all data $\left.=0.1491\right), \mathrm{GOF}=1.021$.

\section{Results and Discussion}

\subsection{Synthesis and characterization of $\mathbf{1}$}

Ligand 1 was readily prepared according to the Kröhnke condensation procedure as for the preparation of 4 -substituted 2,2':6',2"- or 4,2':6',4"-tpy [10,17]. Thus, the room-temperature reaction of 4-hexyloxybenzaldehyde with two equiv. of 2-acetylpyrazine in the presence of $\mathrm{KOH}$ followed by the addition of excess aqueous $\mathrm{NH}_{3}$ for 24 hrs afforded white flurry solid which was isolated with good purity by filtration from the resulting reaction mixture in moderate yield. $\mathbf{1}$ is well soluble in halogenated solvents such as $\mathrm{CH}_{2} \mathrm{Cl}_{2}, \mathrm{CHCl}_{3}$ and chlorobenzene, but only slightly soluble in $\mathrm{MeOH}$, EtOH or MeCN. High resolution mass spectroscopy revealed peak envelops at m/z 434.1943 and 412.2132 assigned to $[\mathrm{M}+\mathrm{Na}]^{+}$and $[\mathrm{M}+\mathrm{H}]^{+}$, respectively, and matched with those calculated. ${ }^{1} \mathrm{H}$ and ${ }^{13} \mathrm{C}$ NMR spectra of $\mathbf{1}$ were recorded in $\mathrm{CDCl}_{3}$ and are consistent with the molecular structures as illustrated in Scheme 1. Good quality crystals of $\mathbf{1}$ appeared as colorless parallel-pipes (defined as polymorph 1a) were readily grown by slow evaporation of a $\mathrm{CH}_{2} \mathrm{Cl}_{2}-\mathrm{MeOH}$ solution, and thus its structure was unambiguously confirmed by single-crystal X-ray diffraction analysis. To explore the potential of this new ligand in forming coordination complexes or networks with transition metals, we performed the reaction of $\mathbf{1}$ with 2 equiv. of silver(I) hexafluorophosphate in a $\mathrm{CH}_{2} \mathrm{Cl}_{2}-\mathrm{MeCN}$ mixture and after slow evaporation of the solvent colorless arrowhead plate crystals were observed. However, $\mathrm{X}$-ray structural analysis revealed that only free ligand of $\mathbf{1}$ was included in the crystals and no metals involved. Interestingly, although the space group is identical to that of $\mathbf{1 a}$, the cell dimensions are clearly distinct with those found in polymorph 1a, which, therefore, represents a new polymorph of $\mathbf{1}$ (polymorph 1b). 


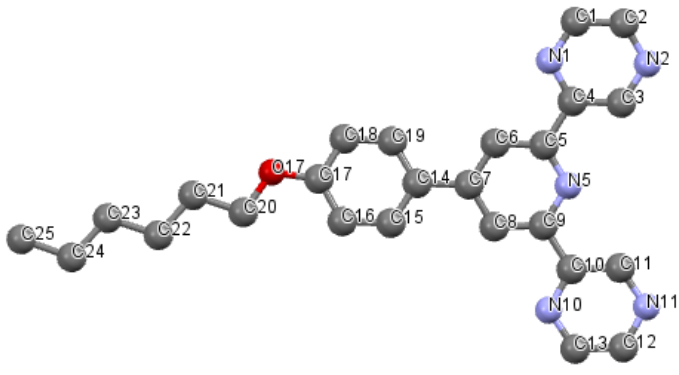

Polymorph 1a

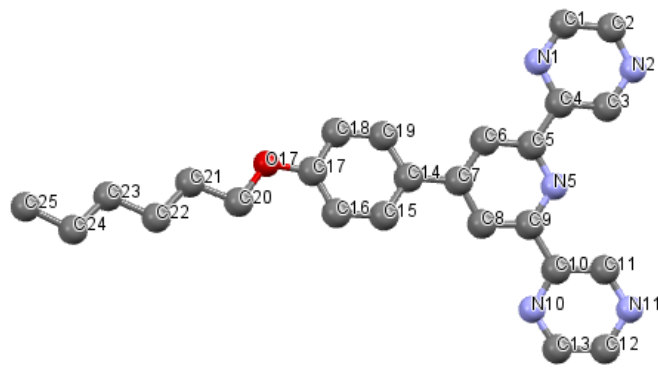

Polymorph $\mathbf{1 b}$

Fig. 1. (a) The X-ray structures of $\mathbf{1}$ observed in polymorphs $\mathbf{1 a}$ and $\mathbf{1 b}$. Selected bond parameters: for 1a, C1-N1 = 1.3340(12), C1-C2 = 1.3917(13), N1-C4 = 1.3413(12), C2-N2 = 1.3373(12), C5-N5 = 1.3369(12), C9-N5 = 1.3398(11), C10-N10 = 1.3378(12), C11-N11 = 1.3355(12), C17-O17 = 1.3606(11), O17-C20 = 1.4375(11) Å; Dihedral angle: C3-C4-C5-N5 = 3.03, C11-C10-C9-N5 = 5.59, C6-C7-C14-C19 = 13.68 ${ }^{\circ}$; for 1b, bond lengths are identical to those in 1a; Dihedral angles: C3-C4-C5-N5 = 0.47, C11-C10-C9-N5 = 7.06, C6-C7-C14-C19 = 12.18 .

\subsection{Structures of two polymorphs of 1}

The structures of independent ligand units existing in polymorphs $\mathbf{1 a}$ and $\mathbf{1 b}$ are presented in Fig. 1, and relevant bond parameters are listed in the caption for comparison. Both $\mathbf{1 a}$ and $\mathbf{1 b}$ crystallize in the triclinic space group P-1 and the asymmetric units contain one ligand molecule. Relevant bond lengths in two polymorphs are essentially identical, and there are only little differences found concerning the torsional angles between four aromatic rings in $\mathbf{1}$. The central pyridine ring and two side pyrazine rings are almost co-planar in both polymorphs $\mathbf{1 a}$ and $\mathbf{1 b}$, whereas the phenyl ring is slightly twisted out of the plane by 13.68 and $12.18^{\circ}$, respectively. This indicates that the polymorphism in $\mathbf{1}$ was not owing to the conformational difference, but rather the intermolecular interactions. Indeed, further inspection reveals that the fashions of molecular arrangement in two polymorphs through significant $\pi$-stacking interactions are remarkably different, which is likely to contribute to the generation of polymorphism of $\mathbf{1}$. As seen in Fig. 2, the $\pi$-stacking in polymorph 1a occurs between the central pyridine and one of the side pyrazinyl groups, while molecules in polymorph $\mathbf{1 b}$ pack via $\pi \ldots \pi$ interactions of two side pyrazine rings. The closest inter-atomic distances for $\pi$-stacking in polymorphs $\mathbf{1 a}$ and $\mathbf{1} \mathbf{b}$ were found to be approximately 3.401 and $3.226 \AA$, respectively. 


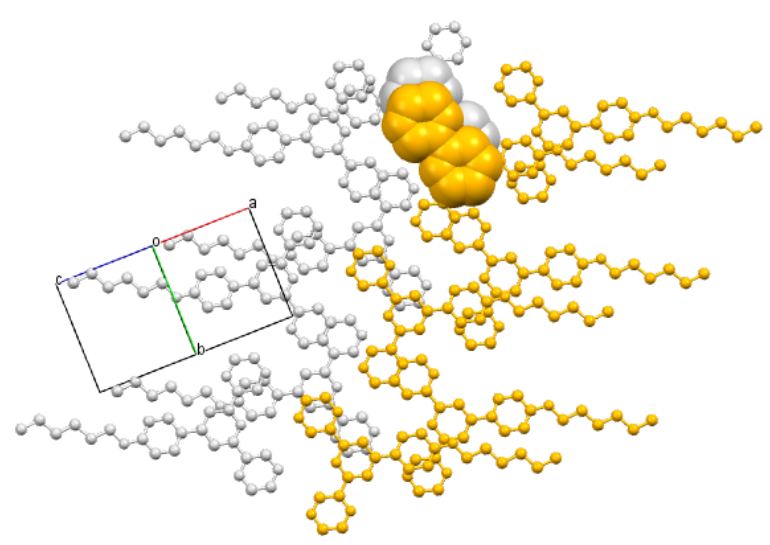

Polymorph 1a

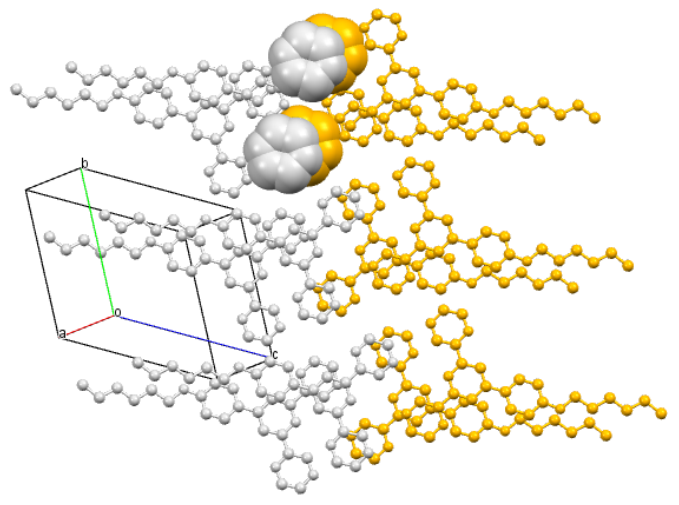

Polymorph 1b

Fig. 2. (a) The distinct molecular packing modes found in polymorphs $\mathbf{1 a}$ and $\mathbf{1 b}$. Partial $\pi$-stacking interactions are presented as space-filling balls.

\subsection{Synthesis and structural analysis of $\mathbf{2}$}

Although the reaction of $\mathbf{1}$ with $\mathrm{AgPF}_{6}$ did not afford any desired metal complex under current conditions, the observation of the new polymorph (polymorph $\mathbf{1 b}$ ) is significant, as it indicates the potential of 2,6-di(pyrazin-2-yl)pyridine derivatives in forming distinct polymorphs by changing the crystallization conditions. According to our previous work on the synthesis of a trinuclear $\mathrm{Cu}^{\mathrm{II}}$ complex based on the closely related compound of $\mathbf{1}$ without a long alkoxy chain [10], we next attempted to conduct the reactions of $\mathbf{1}$ with $\mathrm{CuCl}_{2}$. Thus, carefully layering a methanol solution of $\mathrm{CuCl}_{2} \cdot 2 \mathrm{H}_{2} \mathrm{O}$ onto a solution of $\mathbf{1}$ in $\mathrm{MeOH} / \mathrm{CH}_{2} \mathrm{Cl}_{2}$ gave green crystals of $\mathbf{2}$. X-ray structural analysis reveals that 2 crystallizes in the monoclinic space group $P 2(1) / c$ and there exist two independent molecules in the asymmetric unit, and only one of which is presented in Fig. 3a. Interestingly, 2 features a mononuclear structure, in sharp contrast to the known trinuclear complex [10]. Furthermore, this structure did not change even though the reaction was carried out under a solvothermal condition $\left(120^{\circ} \mathrm{C}\right.$, in acetonitrile), highlighting the role of 4-substituents in $\mathbf{L}$ in affecting the structures and nuclearities of the resulting metal complexes. In 2 , the copper(II) is pentacoordinate residing in the chelating $\mathrm{N}_{3}$ cavity of $\mathbf{1}$ and saturated by two chloride ions. The relevant bond parameters listed in the caption of Fig. 3 are unexceptional and similar to those reported in closely related compounds [10,17]. The coordination geometry around the $\mathrm{Cu}^{\mathrm{II}}$ center can be determined by the distortion parameter $\tau$ value according to the Addison's approach [19], where $\tau$ was defined by the equation, $\tau=(\theta 1-\theta 2) / 60$ ( $\theta 1$ and $\theta 2$ are the largest angles in the coordination sphere; $\tau$ $=0$ represents a perfect square pyramid and $\tau=1$ means a perfect trigonal bipyramid). Hence, the $\tau$ values are calculated to be 0.13 and 0.05 for two independent $\mathrm{Cu}^{\mathrm{II}}$ centers in 2, respectively, indicating square pyramid geometries around $\mathrm{Cu}^{\mathrm{II}}$ centers (Fig. 3). The aromatic regions of 
coordinating ligands in $\mathbf{2}$ were found to be better co-planar than those of free ligand in $\mathbf{1}$. All torsional angles between two adjacent aromatic rings in 2 fall into the ranges of 0.94-5.18 $\AA$ and 0.04-1.66 $\AA$ for two independent molecules, respectively. Furthermore, molecules of $\mathbf{2}$ pack through significant inter-ligand $\pi$-stacking of the aromatic domains (Fig 3b). The $\pi$-stacking occurs both between one of side pyrazine rings and the phenyl ring of two adjacent molecules with a head-to-head arrangement, and between two phenyl rings of molecules with a head-to-tail fashion. The two benzene rings in the latter situation are largely offset, yet the shortest inter-atomic distance for this $\pi$-stacking is as short as $3.344 \AA$.

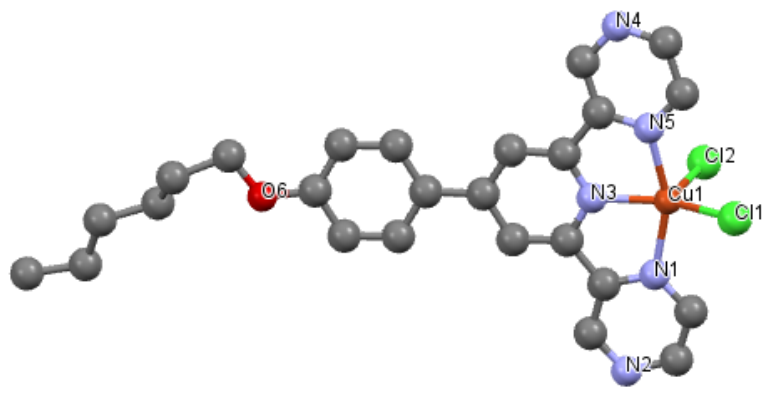

(a)

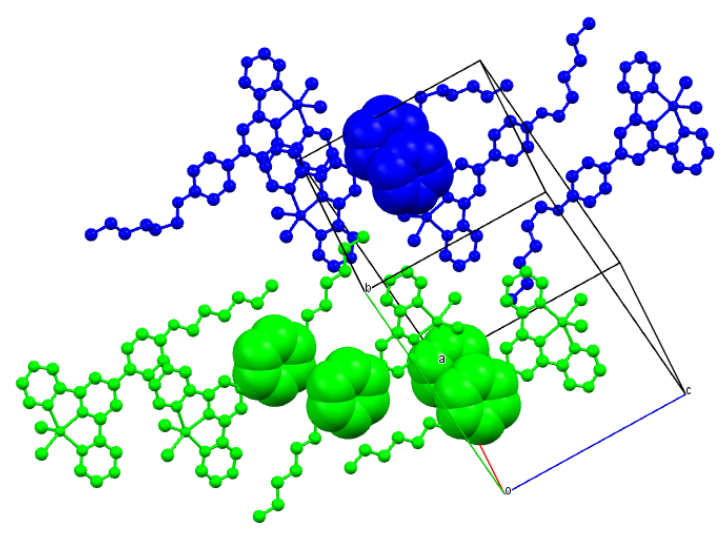

(b)

Fig. 3. (a) The crystal structure of one independent complex in $\mathrm{Cu}(\mathbf{1}) \mathrm{Cl}_{2} \cdot \mathrm{CH}_{3} \mathrm{CN}$ (2). Solvated acetonitrile and hydrogen atoms are omitted for clarity. Selected bond parameters: Cu1-N1 $=2.046(3)$, Cu1-N3 $=1.951(3)$, Cu1-N5 = 2.045(3), $\mathrm{Cu} 1-\mathrm{Cl} 1=2.2232(10), \mathrm{Cu} 1-\mathrm{Cl} 2$ = 2.4413(10) $\AA$; N1-Cu1-N5 = 157.38(12), N1-Cu1-N3 = 79.01(12), N3-Cu1-N5 = 78.90(12), Cl1-Cu1-Cl2 = 107.97(4), Cl1-Cu1-N3 = 149.66(9), N3-Cu1-Cl2 = 102.30(9) ${ }^{\circ}$. (b) The molecular packing mode in 2 . Two sets of independent complexes are illustrated in blue and green, respectively, and partial intermolecular $\pi$-stacking interactions are presented as space-filling balls.

\section{Conclusion}

In summary, we have synthesized and characterized a new derivative of 2,6-di(pyrazin-2yl)pyridine with a long alkoxy chain. Two polymorphs were revealed when the crystals were 
crystallized under different conditions. Intermolecular $\pi$-stacking interactions were observed to be the major driving forces for the generation of polymorphism, rather than the conformational difference. A mononuclear $\mathrm{Cu}^{\mathrm{II}}$ complex featuring only chelating coordination mode was isolated by both layering method and solvothermal reaction, distinct with the trinuclear structure reported in our previous work. The coordination versatility of this type of multidentate nitrogen ligands is worth further investigating.

\section{Acknowledgements}

We acknowledge the City University of New York (CUNY) Collaborative Incentive Research Grant (CIRG\#80209-06) and the Program for Research Initiatives for Science Majors (PRISM) at John Jay College funded by the Title V, HSI-STEM and MSEIP programs within the U.S. Department of Education; the PAESMEM program through the National Science Foundation; and New York State's Graduate Research and Teaching Initiative. The Natural Science Foundation of Hubei Province in China (2015CFA130 and 2013CFA015) is gratefully acknowledged for partial support.

\section{Appendix A. Supplementary data}

Crystallographic data for the structural analysis have been deposited with the Cambridge Crystallographic Data Centre as supplementary publication. CCDC Nos. 1432585-1432587 contain the supplementary Crystallographic data for this paper. These data can be obtained free of charge via http://www.ccdc.cam.ac.uk/conts/retrieving.html (or from the Cambridge Crystallographic Data Centre, 12 Union Road, Cambridge CB2 1EZ, UK; fax: (+44) 1223-336-033; or e-mail: deposit@ccdc.cam.ac.uk).

\section{References}

[1] a) E.C. Constable, Chem. Soc. Rev. 36 (2007) 246; b) D.A. Safin, J.M. Frost, M. Murugesu, Dalton Trans. 44 (2015) 20287.

[2] E.C. Constable, C.E. Housecroft, New J. Chem. 22 (1998) 193.

[3] A. Wild, A. Winter , F. Schlütter, U.S. Schubert, Chem. Soc. Rev. 40 (2011) 1459.

[4] A. Winter, G.R. Newkome, U.S. Schubert, ChemCatChem 3 (2011) 1384.

[5] U.S. Schubert, A. Winter, G.R. Newkome, Terpyridine-Based Materials, Wiley-VCH, Weinheim, Germany 2011, Ch. 4.

[6] Y. Gao, D. Rajwar, A.C. Grimsdale, Macromol. Rapid Commun. 35 (2014) 1727.

[7] A. Winter, M. Gottschaldt, G.R. Newkome, U.S. Schubert, Curr. Top. Med. Chem. 12 (2012) 158.

[8] S. Hayami, Y. Komatsu, T. Shimizu, H. Kamihata,Y.H. Lee, Coord. Chem. Rev. 255 (2011) 1981.

[9] A. Winter, M.D. Hager, G.R. Newkome, U.S. Schubert, Adv. Mater. 23 (2011) 5728.

[10] Z. Yin, G. Zhang, T. Phoenix, S. Zheng, J.C. Fettinger, RSC Adv. 5 (2015) 36156. 
[11] L.J.K. Cook, F. Tunab, M.A. Halcrow, Dalton Trans. 42 (2013) 4254.

[12] a) R. Liegghio, P.G. Potvin, A.B.P. Lever, Inorg. Chem. 40 (2001) 5485; b) A. Stublla, P.G. Potvin, Eur. J. Inorg. Chem. (2010) 3040; c) G.C. Vougioukalakis, T. Stergiopoulos, G. Kantonis, A.G. Kontos, K. Papadopoulos, A. Stublla, P.G. Potvin, P. Falaras, J. Photochem. Photobio A: Chem.214 (2010) 22; d) C. Dares, T. Manivannan, P.G. Potvin, A.B.P. Lever, Inorg. Chim. Acta 374 (2011) 606; e) F.A. Al-mutlaq, P.G. Potvin, A.I. Philippopoulos, P. Falaras, Eur. J. Inorg. Chem. (2007) 2121; f) M. Darabantu, L. Boully, A. Turck, N. Plé, Tetrahedron 61 (2005) 2897; g) S. Vaduvescu, P.G. Potvin, Eur. J. Inorg. Chem. (2007) 2121.

[13] a) J.-W. Dai, Z.-Y. Li, Y.-L. Chen, B. Cai, J.-Z. Wu, Y. Wu, Z. Anorg. Allg. Chem. 636 (2010) 2475; b) J.-W. Dai, B.Z. Li, Y.-L. Chen, G. Huang, B. Cai, Y. Yu, J.-Z. Wu, Inorg. Chem. Comm.13 (2010) 625; c) Y. Shuai, X.-Y. Wang, J.-W. Dai, J.-Z. Wu, Acta Cryst. E70 (2014) o577.

[14] a) E.A. Medlycott, J. Wang, G.S. Hanan, Acta Cryst. E64 (2008) m326; b) J.Wang, G.S. Hanan, Synlett, (2005) 1251; c) U. Ziener, E. Breuning, J.M. Lehn, E. Wegelius, K. Rissanen, G. Baum, D. Fenske, G. Vaughan, Chem. Eur. J. 6 (2000) 4132; d) J. Zadykowicz, P.G. Potvin, J. Coord. Chem. 47 (1999) 395; e) M. A. Halcrow, Coord. Chem. Rev. 249 (2005) 2880.

[15] J.-P. Brog, C.-L. Chanez, A. Crochet, K.M. Fromm, RSC Adv. 3 (2013) 16905.

[16] a) T.L. Threlfall, Analyst 120 (1995) 2435; b) McCrone, W. C. In Polymorphism in Physics and Chemistry of the Organic Solid State; Fox, D., Labes, M. M., Weissemberg, A., Eds.; Interscience: New York, 1965; Vol. II, p 726; c) Bernstein, J. In Organic Solid State Chemistry; Desiraju, G. R. Ed.; Elsevier: Amsterdam, 1987; p 471; d) Braga, D.; Grepioni, F. Chem. Soc. Rev. 29 (2000) 229; e) Mei, X.; Wolf, C. Cryst. Growth Des. 4 (2004) 1099; f) G. Zhang, G. Yang, N. Wu, J.S. Ma, Cryst. Growth Des. 6 (2006) 229; g) G. Zhang, CrystEngComm 15 (2013) 6453.

[17] a) G. Zhang, Y. Jia, W. Chen, W. F. Lo, N. Brathwaite, J.A. Golen, A.L. Rheingold, RSC Adv. 5 (2015) 15870; b) G. Zhang, J. Tan, Y.Z. Zhang, C. Ta, S. Sanchez, S.-Y. Cheng, J.A. Golen, A.L. Rheingold, Inorg. Chim. Acta 435 (2015) 147; c) G. Zhang, E. Liu, C. Yang, L. Li, J.A. Golen, A.L. Rheingold, Eur. J. Inorg. Chem. (2015) 939.

[18] a) Z. Yin, S. Zhang, S. Zheng, J.A. Golen, A.L. Rheingold, Polyhedron 101 (2015) 139; b) E.C. Constable, G. Zhang, C.E. Housecroft, J. A. Zampese, Inorg. Chem. Comm. 15 (2012) 113; c) E.C. Constable, G. Zhang, C.E. Housecroft, J.A. Zampese, CrystEngComm 13 (2011) 6864; d) E.C. Constable, G. Zhang, C.E. Housecroft, M. Neuburger, J.A. Zampese, CrystEngComm 12 (2010) 3733.

[19] A.W. Addison, T.N. Rao, J. Reedijk, J.Van Rijn, G.C. Verschoor, J. Chem. Soc., Dalton Trans. (1984) 1349. 


\section{Graphic Abstract—pictogram}

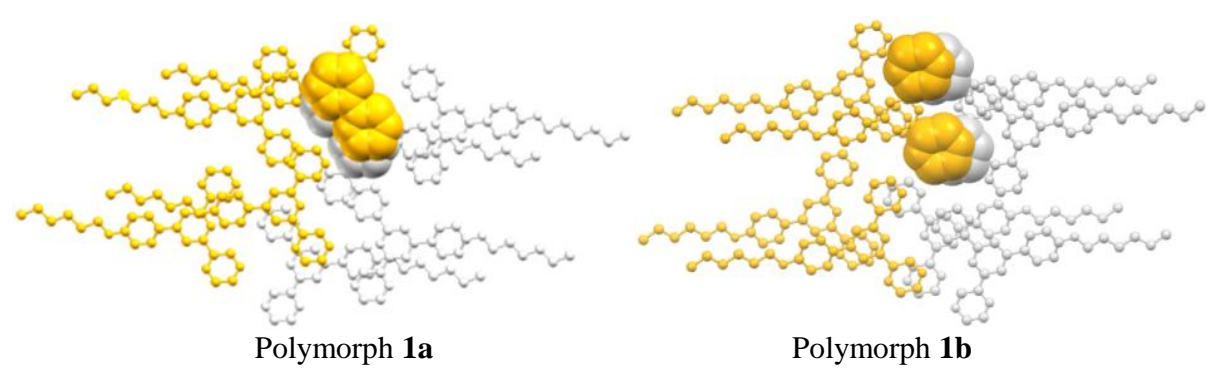

